\title{
Managed Care and Outpatient Substance Abuse Treatment Intensity
}

\author{
Christy Harris Lemak, PhD \\ Jeffrey A. Alexander, PhD
}

\begin{abstract}
This study examines the extent to which managed care behavioral controls are associated with treatment intensity in outpatient substance abuse treatment facilities. Data are from the 1995 National Drug Abuse Treatment System Survey, a nationally representative survey that includes over 600 provider organizations with a response rate of $86 \%$. Treatment intensity is measured in three ways: (1) the number of months clients spend in outpatient drug treatment, (2) the number of individual treatment sessions clients receive over the course of treatment, and (3) the number of group treatment sessions clients receive over the course of treatment. After accounting for selection bias and controlling for market, organization, and client characteristics, there is no significant relationship between the scope of managed care oversight and treatment intensity. However, the stringency of managed care oversight activities is negatively associated with the number of individual and group treatment sessions received over the course of treatment.
\end{abstract}

\section{Introduction}

Managed behavioral care programs have the potential to dramatically alter mental health and substance abuse treatment practices by influencing the practice patterns of providers within the defined network..$^{1,2}$ There has been rapid growth of managed care in this sector over the past decade. It is estimated that by the end of 1999, the mental health and substance abuse benefits of nearly 177 million people were included in managed behavioral care programs, a $23 \%$ increase from the previous year. ${ }^{3}$ In the public sector, many Medicaid programs also are implementing managed care programs for mental health and substance abuse conditions. ${ }^{4}$ As managed care becomes more prevalent in behavioral health, there is increasing interest in whether or not and how this form of financing and delivery affects treatment practices. ${ }^{5}$ In particular, concern has been expressed about whether managed care, with its emphasis on cost control, affects the intensity of substance abuse treatment. Drug treatment intensity encompasses both the length of time clients spend in treatment and the amount or number of visits received during treatment.

Substance abuse treatment intensity is important for several reasons. First, longer treatment is the most important predictor of various post-treatment outcomes, including reduced drug use, fewer arrests, improved employment outcomes, and fewer subsequent readmissions. A recent exhaustive

Address correspondence to Christy Harris Lemak, PhD, Assistant Professor, Department of Health Services Administration, University of Florida, P.O. Box 100195, Gainesville, FL 32610-0195. Telephone (352) 392-6915, fax (352) 392-7109, e-mail clemak@hp.ufl.edu.

Jeffrey A. Alexander, PhD, is the Richard Carl Jelenik Professor in the Department of Health Management and Policy at the University of Michigan.

Journal of Behavioral Health Services \& Research, 2001, 28(1), 12-29. (C) 2001 National Council for Community Behavioral Healthcare. 
literature review revealed that this association holds for clients with a wide range of addiction problems receiving treatment in every substance abuse treatment modality. ${ }^{6-13}$ Further, the number of sessions of drug treatment received during treatment is consistently found to improve abstinence and other important treatment outcomes. ${ }^{14-18}$ Last, in their efforts to reduce the costs of behavioral health services, managed care firms may specifically limit treatment intensity through benefit package design, utilization review, and other oversight activities. ${ }^{19}$

Surprisingly, little is known about the impact of managed care on substance abuse treatment. ${ }^{19}$ There have been relatively few studies of the effects of managed behavioral care on substance abuse treatment providers, ${ }^{20-26}$ and few comprehensive studies focus specifically on managed care activities and effects in outpatient settings, the predominant form of substance abuse treatment. ${ }^{27}$ This research builds on the authors' previous work in the area of managed care and substance abuse treatment in the following ways. First, the effects of two dimensions of managed care oversight that were developed in previous research ${ }^{23,25}$ are empirically tested in the current study. Second, the authors' previous research ${ }^{25,26}$ examined the effects of managed care on two organizational phenomena: administrative burden and technical efficiency. Based on their prior findings, the authors now extend the conceptual model and examine managed care's effects on treatment intensity for the first time. The specific aim of this study is to fill the gaps in previous research by providing a comprehensive, national examination of the effects of managed care on the intensity of outpatient substance abuse treatment.

\section{Conceptual Model}

Managed care firms use a variety of controls to ensure that substance abuse services provided in outpatient substance abuse treatment (OSAT) units are consistent with their own objectives. These managed care oversight mechanisms typically serve to control access to care and regulate the amount, type, or quality of care. ${ }^{2}$ Oversight mechanisms may include various forms of utilization review, treatment planning, precertification, or limits on the number of visits that may be provided.

The scope of managed care oversight is defined as the extent or reach of oversight mechanisms in place in a provider organization. In some units, managed care oversight activities may affect only a small percentage of total clients. In other units, however, oversight activities apply to a large percentage of the client base. Furthermore, some units are required to respond to many different types of oversight including utilization review, specific treatment plans, and client follow-up, while in other units managed care firms employ fewer types of oversight activities. When more clients are covered by more managed care oversight requirements, OSAT units have fewer opportunities to set and maintain treatment practices without external influence and thus may be forced to reduce treatment intensity for managed care clients. This suggests Hypothesis 1:

H1: The greater the scope of managed care oversight, the lower is the intensity of outpatient substance abuse treatment.

The stringency of managed care oversight refers to the level of constraints imposed by managed care oversight mechanisms on treatment providers. For example, when managed care firms place stringent rules on the number of visits authorized, providers have fewer alternatives regarding their responses to the requirements. When such oversight is less strict, however, providers have more opportunities to define compliance with demands and, therefore, maintain more discretion in responding to the external requirements. Although many managed care firms place limits on the number of visits that are authorized for payment, there is considerable variation in the number of visits authorized and in the potential responses of OSAT units. For example, OSAT providers facing stringent visit limits may continue to provide treatment services even though they are not being reimbursed for such care. OSAT units may be more likely to respond to managed care demands when visit limits are more stringent. This suggests Hypothesis 2: 
H2: The greater the stringency of managed care oversight, the lower is the intensity of outpatient substance abuse treatment.

\section{Alternative Explanations}

Aspects of the market or environment, characteristics of the organization, and attributes of clients also may explain variation in client intensity to treatment among OSAT units; thus, they are potential alternative explanations to the hypothesized relationships between managed care scope, managed care stringency, and treatment intensity.

Market forces and other environmental conditions could explain treatment intensity because they may force providers to demonstrate best practices or reduce treatment intensity in order to remain cost competitive. For example, in markets with greater health maintenance organization (HMO) or managed care penetration, units may not have access to clients and revenues from other, nonmanaged payers such as private pay or indemnity insurance.

Treatment practices of OSAT units may be determined in part by the organization's embeddedness in a larger administrative structure, its overall mission, and its approach to its markets. More specifically, the percentage of revenues covered by managed care and the number of managed care clients in the unit may indicate a greater dependence on managed care firms and may thus be associated with treatment intensity. ${ }^{28}$ The uncertain nature of substance abuse treatment means that treatment practices are determined to a great extent by the treatment staff. ${ }^{29.30}$ In addition, OSAT organizations are embedded in "complex networks consisting of state and federal agencies, professional associations and advocacy groups, and licensing and funding groups" and thus, accreditation status may be associated with treatment intensity. ${ }^{30(0638)}$

Further, treatment organizations that are owned or managed by other organizations such as hospitals and mental health centers may exhibit different treatment practices than unaffiliated providers. Affiliated organizations may rely on larger, sponsoring organizations for scarce resources or to negotiate terms with resource providers on their behalf. ${ }^{31}$ Even when pressures from external actors are great, an organization may be more likely to resist external pressures that conflict with its mission. ${ }^{32}$ Finally, because they may be committed to client needs regardless of external pressures, not-for-profit and public OSAT organizations may have differing responses to the demands of managed care firms regarding treatment intensity. ${ }^{33}$

The ongoing nature of methadone treatment services will lead to different levels of treatment intensity for methadone versus non-methadone units. Specifically, clients receiving methadone services are likely to remain in treatment longer and receive a different mix of individual and group treatment sessions over the course of treatment. ${ }^{34}$

Last, units treating clients with more severe or complex drug problems may exhibit greater treatment intensity because these clients require more treatment resources to address their needs. The model includes two control measures related to client mix: prior treatment for substance abuse and unemployment. ${ }^{35-40}$

\section{Methods}

\section{Sample and data collection}

This study uses data from the National Drug Abuse Treatment System Survey (NDATSS), a longitudinal program of research into the organizational structures, operating characteristics, and treatment modalities of outpatient substance abuse treatment units in the United States. In the NDATSS, an OSAT unit is formally defined as a physical facility with resources dedicated primarily $(>50 \%$ ) to treating individuals with substance abuse problems (including alcohol and other drugs) on a non-residential basis. The sample was specifically designed to encompass the wide variety of organizations that comprise the nation's complex outpatient treatment system. OSAT units operated 
by the military, the Department of Veterans Affairs, and those that target inmate populations in jails and prison settings are excluded from the survey population.

A systematic random sample of OSAT units was selected for participation from the 1994 through 1995 National Frame of Substance Abuse Treatment Programs (NFSATP), a national database of inpatient and outpatient substance abuse treatment programs compiled by the Institute for Social Research (ISR) at the University of Michigan in 1994. These units were combined with panel units that had been sampled as part of prior waves of NDATSS. In each wave, the sample is nationally representative and stratified by public/private status, treatment modality (methadone or nonmethadone), and organizational affiliation (hospital, mental health center, other). After screening and non-response, the total number of organizations completing interviews in 1995 was 618 , for a combined response rate of $85.6 \%$.

Several steps were taken during instrument development to validate interview items: extensive review of the managed care and substance abuse treatment research literature, site visits to several treatment units, and two pre-tests with nationally representative samples ( $n=20$ units) of each. Further, interviewers conducted in vivo checks on interview responses and used frequent probes and follow-up questions. In addition, study staff conducted internal consistency checks of key numbers (eg, numbers of clients) and, if necessary, called respondents back to clarify responses and address problems. In short, the study staff used telephone survey procedures that extensive research ${ }^{41}$ indicates will produce highly reliable and valid data.

The director and clinical supervisor of each participating OSAT unit were asked to complete telephone interviews. Directors provided information concerning the unit's control status, environment, finances, parent units, and managed care arrangements. Clinical supervisors provided information about staff, clients, treatment practices, and services provided. After the data were collected, extensive reliability checks were performed within each survey. Results also were compared between surveys to further confirm validity. These checks revealed very high levels of consistency in the NDATSS data. ${ }^{42}$

\section{Data validity}

Research investigators have examined the validity of the data obtained from the NDATSS interviews by comparing these data to those of the Drug Services Research Study (DSRS), a national client-level investigation of drug treatment organizations. Specifically, data on treatment duration from 323 methadone treatment units in the 1990 NDATSS closely matched findings obtained from discharge abstracts from 520 outpatient methadone units in the 1990 DSRS. ${ }^{43}$

\section{Measures}

\section{Dependent variables}

Treatment intensity encompasses the length of treatment and the amount, or number, of sessions clients receive during treatment. While treatment intensity typically implies clinical services per unit of time, in this article the two components of the ratio are separated, allowing for a more precise understanding of the effects of managed care on both duration and amount of treatment. Specifically, treatment duration is operationalized as the average number of months in outpatient substance abuse treatment, a commonly used measure of treatment length. ${ }^{44}$ The clinical supervisor of each OSAT unit reported the average number of months substance abuse clients received outpatient treatment in their unit. The amount of treatment is measured as the number of individual treatment sessions and group treatment sessions received over the entire course of treatment. The administrative director of each OSAT unit reported these variables in aggregate. Due to the skewed nature of the distribution of the three dependent variables, a natural $\log$ transformation of each was taken and used in the analyses. 


\section{Independent variables}

Scope of managed care oversight takes into account the degree to which six different oversight activities are in force in each OSAT unit. The measure is the sum of the percentages of total managed care clients for whom (1) managed care arrangements require written correspondence for precertification, (2) managed care arrangements specify the content of the ongoing treatment plan, (3) managed care arrangements specify that correspondence regarding authorization of sessions be conducted with a treatment staff member, (4) managed care arrangements require client follow-up by the treatment organization after discharge, (5) managed care arrangements require some limit on the number of authorized visits, and (6) managed care arrangements disallow claims after services have been provided.

In the 1995 NDATSS, limiting the number of visits is the most prevalent form of managed care oversight. OSAT units reported that, on average, $73 \%$ of their managed care clients are subject to some type of visit limits from the managed care firm. Managed care firms also dictate the nature of the utilization review process. Specifically, OSAT units report that, on average, $34 \%$ of their managed care clients were subject to requirements that at least some of the utilization review correspondence be in writing, as compared with telephone calls to the managed care organization. Further, for over $56 \%$ of managed care clients managed care firms specify that utilization review correspondence must occur with a member of the treatment staff and not with clerical or administrative personnel assigned to such activities.

Managed care firms also are involved in the specification of the nature and type of treatment to be reimbursed. On average, OSAT units reported that managed care firms specify the content of treatment plans for $37 \%$ of managed care clients and require follow-up with clients after discharge for $30 \%$ of all managed care cases. The use of sanctions was less prevalent among the 1995 NDATSS sample. OSAT units reported that managed care firms disallowed claims after treatment ended for an average $31 \%$ of managed care clients.

Stringency of managed care oversight is operationalized as a weighted average of the total number of visits authorized by managed care firms for the OSAT unit. The weighted average for each unit is based on questions that asked for the percentage of managed care clients with visit limits in four categories, ranging from those with limits greater than 20 visits to those with limits of five or fewer visits. The weights were assigned as follows: $>20$ visits: weighted $1 ; 11$ to 20 visits: weighted $2 ; 6$ to 10 visits: weighted 3 ; and $\leq 5$ visits: weighted 4 . Thus, OSAT units with a higher weighted average have more clients with more stringent visit limits than units with a lower weighted average on this measure. In 1995, OSAT units reported that, on average, $19 \%$ of managed care clients had no visit limits, $39 \%$ had more than 20 visits authorized, $30 \%$ had 11 to 20 visits authorized, $11 \%$ had 6 to 10 visits authorized, and $5 \%$ of the clients had the most stringent visit limits, with five or fewer OSAT visits authorized.

Other definitions employed in this study are as follows:

- HMO penetration in the market is measured as the percentage of the total county population enrolled in HMOs in 1995. The source for these data is a national database compiled by Sachs Group, Inc (Evanston, Illinois), a health care information firm.

- Percentage of revenues covered by managed care is measured as the percentage of total OSAT unit revenues covered by various forms of managed care in 1995.

- Number of managed care clients is the number of OSAT clients covered by some form of managed care in 1995.

- Professional staff is the percentage of total treatment staff with professional training. This concept is measured as the total treatment staff with master's or doctorate $(\mathrm{MD}, \mathrm{PhD})$ degrees divided by the total number of treatment staff in each OSAT unit. 
- Joint Commission on Accreditation of Healthcare Organizations (Joint Commission) accreditation is a dummy variable indicating the units that are accredited by the Joint Commission. Units with such accreditation are coded 1 ; all other units are coded 0.

- Unit affiliation is captured as whether the OSAT unit is free-standing or affiliated with a hospital or mental health center. Affiliation occurs if the unit is owned by, managed by, or affiliated with a hospital or mental health center. Such affiliations are measured by two dummy variables; free-standing or "other" affiliation is the referent category.

- Ownership is expressed in three categories: private, not-for-profit; private, for-profit; and public. Two dummy variables are included in the model; public ownership is the referent category.

- Methadone modality is measured by a single dummy variable. Units that offer methadone treatment are coded 1; all other units are coded 0.

- Client mix is captured by two variables. Percentage of clients unemployed is measured as the percentage of all OSAT clients who were unemployed. Percentage of clients with some prior treatment is measured as the percentage of all OSAT clients who have received some prior treatment for substance abuse.

\section{Analysis strategy}

\section{Descriptive analyses}

One aim of this article is to understand how various managed care activities are related to outpatient substance abuse treatment intensity. First, treatment intensity levels for all OSAT units in the NDATSS sample, as well as a comparison of treatment intensity for managed care and non-managed care units, are presented. Next, because methadone treatment units may have different levels of treatment intensity and different managed care activity, differences in treatment intensity for methadone units in managed care and methadone units not involved in managed care are investigated.

\section{Sample selection regression analyses}

Because all units did not report managed care activity, the managed care subsample may no longer be representative. It is possible that some form of selectivity occurs for OSAT units to become involved in managed care. Thus, the parameter estimates in an equation predicting treatment practices may be biased, inconsistent, and inefficient because the relationship between managed care participation and the treatment practice has not been taken into account. Generally, this problem is referred to as a sample selection problem. ${ }^{45,46}$

To address the issues related to sample selection, the effects of managed care on treatment duration are estimated using a two-equation maximum likelihood approach ${ }^{46}$ For each dependent variable, there are two sets of explanatory variables. One set, called the participation equation, explains whether or not OSAT units participate in managed care. A second set of variables, the regression equation, explains the observed level of one of three measures of treatment intensity. The predictors in the second set are only observed if an OSAT unit participates in managed care. The participation model used in this analysis has been developed elsewhere ${ }^{47}$ and is described in Appendix A.

\section{Results}

\section{Descriptive results}

\section{Treatment intensity}

Unadjusted descriptive data suggest that there are differences in the treatment practices of units involved in managed care compared with those not involved in managed care. As shown in Table 1, the 


\section{Table 1}

Treatment intensity for outpatient substance abuse treatment organizations (1995) comparing managed care (MC) and non-managed care, methadone and non-methadone units

\begin{tabular}{|c|c|c|c|c|c|c|}
\hline & \multicolumn{2}{|c|}{$\begin{array}{c}\text { All } \\
(n=618)\end{array}$} & \multicolumn{2}{|c|}{$\begin{array}{c}\text { MC Yes } \\
(n=\mathbf{2 3 6})\end{array}$} & \multicolumn{2}{|c|}{$\begin{array}{c}\text { MC No } \\
(n=382)\end{array}$} \\
\hline & Mean & SD & Mean & SD & Mean & SD \\
\hline \multicolumn{7}{|l|}{ All units } \\
\hline Months in treatment & 9.78 & 12.97 & 7.84 & 10.19 & 10.98 & 14.32 \\
\hline Individual treatment sessions & 34.55 & 67.16 & 26.29 & 40.70 & 39.99 & 79.54 \\
\hline \multirow[t]{3}{*}{ Group treatment sessions } & 49.44 & 86.70 & 50.50 & 95.74 & 48.68 & 79.80 \\
\hline & \multicolumn{2}{|c|}{$\begin{array}{c}\text { All } \\
(n=119)\end{array}$} & \multicolumn{2}{|c|}{$\begin{array}{c}\text { MC Yes } \\
(n=31)\end{array}$} & \multicolumn{2}{|c|}{$\begin{array}{l}\text { MC No } \\
(n=88)\end{array}$} \\
\hline & Mean & SD & Mean & SD & Mean & SD \\
\hline \multicolumn{7}{|l|}{ Units providing methadone } \\
\hline Months in treatment & 23.50 & 22.50 & 20.52 & 21.04 & 24.58 & 23.01 \\
\hline Individual treatment sessions & 94.13 & 120.94 & 79.73 & 80.37 & 99.47 & 133.01 \\
\hline \multirow[t]{3}{*}{ Group treatment sessions } & 69.74 & 103.02 & 89.01 & 147.14 & 60.84 & 74.33 \\
\hline & \multicolumn{2}{|c|}{$\begin{array}{c}\text { All } \\
(n=\mathbf{4 8 5})\end{array}$} & \multicolumn{2}{|c|}{$\begin{array}{l}\text { MC Yes } \\
(n=\mathbf{2 0 0})\end{array}$} & \multicolumn{2}{|c|}{$\begin{array}{c}\text { MC No } \\
(n=285)\end{array}$} \\
\hline & Mean & SD & Mean & SD & Mean & SD \\
\hline \multicolumn{7}{|l|}{ Units not providing methadone } \\
\hline Months in treatment & 6.20 & 4.58 & 5.81 & 4.65 & 6.47 & 4.52 \\
\hline Individual treatment sessions & 22.33 & 39.80 & 19.27 & 25.07 & 24.57 & 47.71 \\
\hline Group treatment sessions & 45.23 & 82.42 & 44.72 & 84.47 & 45.63 & 80.97 \\
\hline
\end{tabular}

$\mathrm{SD}$, standard deviation

average months in treatment for the entire sample of NDATSS units is 9.78 months. OSAT units with managed care have a shorter treatment duration ( 7.84 months) than those without managed care (10.98 months). Further, the average number of individual treatment sessions over the course of treatment is 34.55 , and the average group sessions received over the course of treatment is 49.44 .

Units with managed care provide, on average, fewer total individual treatment sessions (26.29 sessions versus 39.99 sessions) and about the same number of group treatment sessions than units without managed care ( 50.50 session versus 48.68 sessions).

\section{Treatment intensity: Managed care in methadone and non-methadone units}

Table 1 also shows treatment intensity for methadone and non-methadone units in the sample. On average, clients in methadone units experienced greater treatment intensity than clients in nonmethadone units. Specifically, clients in methadone units stay an average of 23.5 months (compared with 6.2 for non-methadone units) and received 94.13 individual treatment sessions and 69.74 group sessions (compared with 22.33 individual sessions and 45.23 group sessions for clients in nonmethadone units). When comparing treatment intensity for managed care versus non-managed care units, the pattern of findings described above generally holds within the methadone and the non- 
methadone subsets. Specifically, clients in methadone units with managed care stayed for fewer months, received fewer individual treatment sessions, and received more group treatment sessions than clients in methadone units without managed care. Similarly, clients in non-methadone units with managed care experienced fewer months in treatment and fewer individual treatment sessions than clients in non-methadone, non-managed care units. There was no difference in the average group treatment sessions received over the course of treatment between managed care and non-managed care organizations that do not provide methadone services. In conclusion, differences in treatment intensity exist between units with managed care and units without managed care, and these differences hold for both methadone and non-methadone units in the sample.

\section{Managed care}

Table 2 presents descriptive statistics and bivariate correlations for all main model variables. Results from this national sample of organizations indicate that $38 \%(n=236)$ of all OSAT organizations were involved in some form of managed care in 1995. Treatment units involved in managed care received, on average, $46 \%$ of their revenues from managed care arrangements and reported 191 clients covered by some form of managed care.

\section{Participation model: Effects on unit participation in managed care}

The participation model is discussed in detail in the appendix and descriptive data are provided (Table A-2). Table 3 presents the results of the sample selection regression. For two of the three dependent variables (months in treatment and individual treatment sessions received over the course of treatment), there is evidence of sample selection bias. For the model of group treatment sessions over the course of treatment, however, there appears to be no systematic selection effect.

There are two environmental characteristics in the model. The extent of competition shows a significant positive relationship in all three models, while the HMO penetration of the market is not systematically associated with managed care participation.

In general, there are consistent patterns of relationships between organizational characteristics and unit involvement in managed care. In all three models, organizational size, the proportion of referrals from health care providers and employee assistance programs, and private ownership status (for-profit and not-for-profit) show significant, positive relationships with unit participation in managed care. By contrast, the methadone treatment modality shows a consistent, negative relationship with managed care participation in each of the three models. There is some evidence that hospital affiliation is positively associated with managed care participation in two models (months in treatment and group treatment sessions). Joint Commission accreditation status displays a marginally significant and positive relationship with managed care participation in the months in treatment and individual treatment session equations only. There are no significant relationships for two participation model predictors (HMO penetration in the market and affiliation with a mental health center).

\section{Main effects model: Managed care and treatment intensity}

After controlling for selection effects, as well as market, organization, and client characteristics, there is no significant relationship between the scope of managed care oversight and treatment intensity (see top section of Table 3). There is evidence, however, supporting the hypothesis that the stringency of managed care oversight activities is negatively associated with treatment intensity. Specifically, oversight stringency has a significant, negative relationship with the number of individual treatment sessions $(p<.05)$ and number of group treatment sessions $(p<.05)$ received over the course of treatment.

The HMO penetration in the market has no significant relationship with months in treatment and number of individual treatment sessions. However, $\mathrm{HMO}$ penetration is marginally associated with 


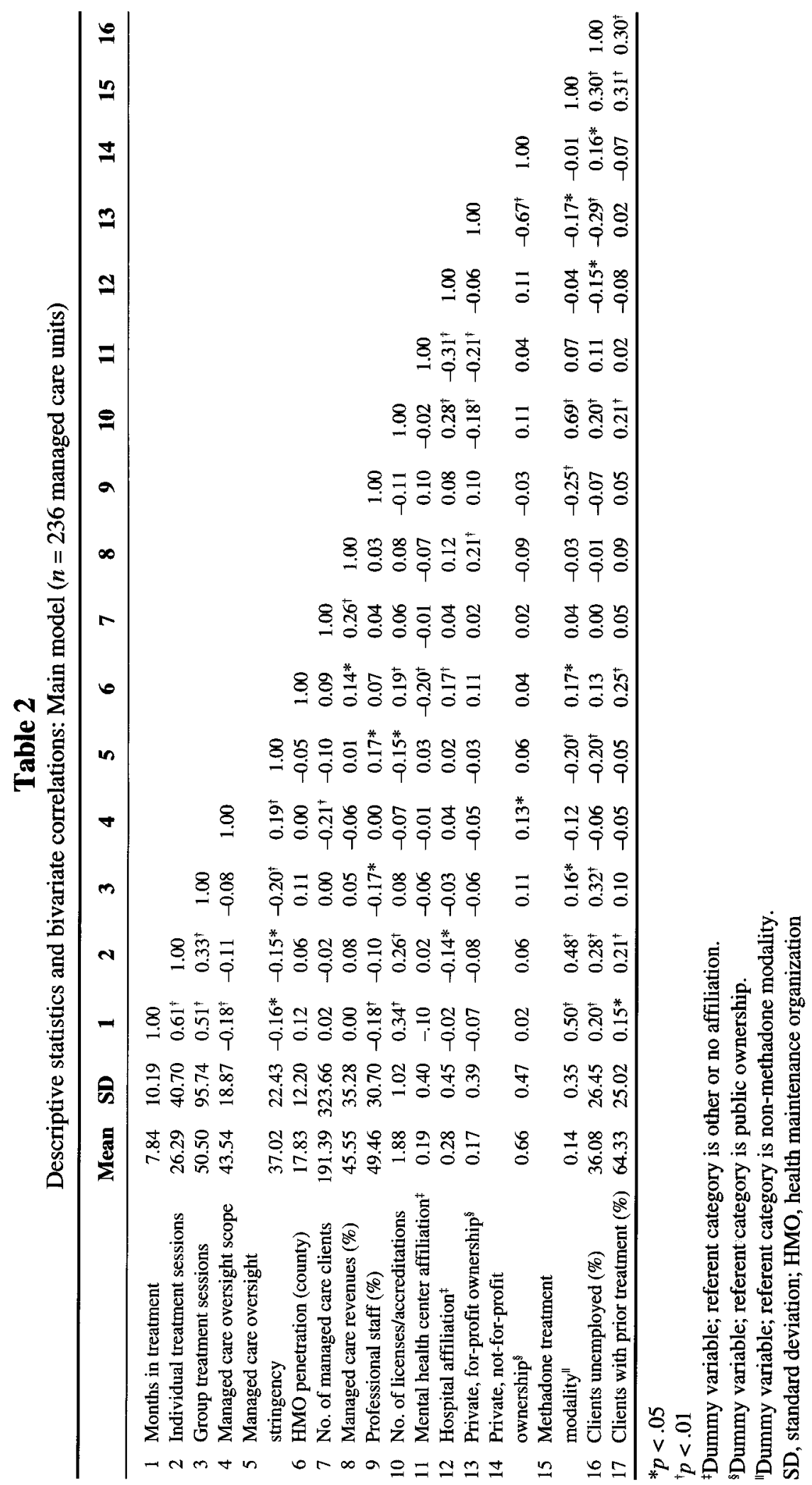


Table 3

Results of sample selection regression

\begin{tabular}{|c|c|c|c|c|c|c|c|c|c|}
\hline & \multicolumn{3}{|c|}{$\begin{array}{l}\text { Months treatment } \\
(n=557 \text { units })\end{array}$} & \multicolumn{3}{|c|}{$\begin{array}{l}\text { Individual sessions } \\
\quad(n=559 \text { units })\end{array}$} & \multicolumn{3}{|c|}{$\begin{array}{l}\text { Group sessions } \\
(n=559 \text { units })\end{array}$} \\
\hline & Coeff & SE & Sig & Coeff & SE & Sig & Coeff & SE & Sig \\
\hline \multicolumn{10}{|l|}{ Main model } \\
\hline Managed care oversight scope & 0.001 & 0.003 & & 0.003 & 0.003 & & 0.000 & 0.003 & \\
\hline \multicolumn{10}{|l|}{ Managed care oversight } \\
\hline stringency & -0.003 & 0.002 & & -0.006 & 0.003 & + & -0.008 & 0.003 & + \\
\hline HMO penetration (county) & 0.005 & 0.005 & & -0.007 & 0.006 & & 0.009 & 0.005 & $*$ \\
\hline No. of managed care clients & 0.000 & 0.000 & & 0.000 & 0.000 & & -0.001 & 0.000 & \\
\hline Managed care revenues $(\%)$ & 0.003 & 0.002 & * & 0.003 & 0.002 & & 0.003 & 0.002 & \\
\hline Professional staff (\%) & 0.000 & 0.002 & & 0.003 & 0.002 & & -0.005 & 0.002 & $t$ \\
\hline No. of licenses/accreditations & -0.017 & 0.084 & & 0.018 & 0.105 & & -0.082 & 0.092 & \\
\hline Mental health center affiliation" & -0.035 & 0.147 & & -0.254 & 0.181 & & -0.038 & 0.163 & \\
\hline Hospital affiliation" & -0.180 & 0.153 & & -0.007 & 0.189 & & -0.118 & 0.166 & \\
\hline Private, for-profit ownership** & 0.119 & 0.229 & & 0.343 & 0.295 & & 0.442 & 0.253 & $*$ \\
\hline \multicolumn{10}{|l|}{ Private, not-for-profit } \\
\hline ownership ${ }^{* *}$ & -0.011 & 0.162 & & 0.322 & 0.203 & & 0.303 & 0.183 & \\
\hline Methadone treatment modality ${ }^{\dagger \dagger}$ & 0.811 & 0.268 & * & 0.978 & 0.349 & $\ddagger$ & 0.513 & 0.290 & * \\
\hline Clients unemployed (\%) & 0.005 & 0.002 & & 0.004 & 0.003 & & 0.008 & 0.003 & $\$$ \\
\hline Clients with prior treatment $(\%)$ & -0.001 & 0.002 & & 0.004 & 0.003 & & 0.001 & 0.003 & \\
\hline Constant & 1.040 & 0.379 & $\ddagger$ & 1.226 & 0.492 & $\dagger$ & 3.125 & 0.410 & 8 \\
\hline \multicolumn{10}{|l|}{ Participation model (probit) } \\
\hline HMO penetration (county) & -0.001 & 0.005 & & -0.002 & 0.005 & & 0.001 & 0.005 & \\
\hline Competition & 0.242 & 0.061 & $\S$ & 0.209 & 0.061 & $\ddagger$ & 0.259 & 0.062 & $\S$ \\
\hline Hospital affiliation" & 0.359 & 0.213 & * & 0.256 & 0.207 & & 0.369 & 0.217 & * \\
\hline Mental health center affiliation" & 0.197 & 0.151 & & 0.129 & 0.151 & & 0.176 & 0.152 & \\
\hline Size (FTE log) & 0.348 & 0.076 & $\$$ & 0.351 & 0.071 & $\S$ & 0.346 & 0.078 & $\S$ \\
\hline Methadone treatment modality ${ }^{\dagger \dagger}$ & -0.667 & 0.176 & $\$$ & -0.777 & 0.176 & $\$$ & -0.672 & 0.174 & $\S$ \\
\hline Referrals HC providers/EAPs (\%) & 0.012 & 0.003 & $\S$ & 0.009 & 0.003 & $\ddagger$ & 0.011 & 0.003 & $\S$ \\
\hline Joint Commission accreditation ${ }^{88}$ & 0.320 & 0.185 & * & 0.390 & 0.174 & $\dagger$ & 0.318 & 0.191 & \\
\hline Private for-profit ownership** & 0.841 & 0.227 & 8 & 0.939 & 0.226 & $\S$ & 0.818 & 0.228 & 8 \\
\hline \multicolumn{10}{|l|}{ Private, not-for-profit } \\
\hline ownership** & 0.317 & 0.153 & $\dagger$ & 0.345 & 0.154 & $\dagger$ & 0.335 & 0.153 & + \\
\hline Constant & -1.814 & 0.248 & $\S$ & -1.767 & 0.241 & $\S$ & -1.835 & 0.251 & $\$$ \\
\hline Lambda & 0.411 & 0.163 & + & 0.740 & 0.232 & 末 & -0.032 & 0.182 & \\
\hline Rho & 0.506 & & & 0.725 & & & -0.038 & & \\
\hline \multicolumn{10}{|l|}{$* p<.10$} \\
\hline \multicolumn{10}{|l|}{$p<.05$} \\
\hline \multicolumn{10}{|l|}{${ }^{\ddagger} p<.01$} \\
\hline \multicolumn{10}{|l|}{${ }_{p}<.001$} \\
\hline \multicolumn{10}{|c|}{ Dummy variable; referent category is other or no affiliation. } \\
\hline \multicolumn{10}{|c|}{ **Dummy variable; referent category is public ownership. } \\
\hline \multicolumn{10}{|c|}{${ }^{*}$ Dummy variable; referent is non-methadone treatment modality. } \\
\hline \multicolumn{10}{|c|}{$\$$ Dummy variable; referent category is no Joint Commission accreditation. } \\
\hline coefficient; SE, standard error; & gni & 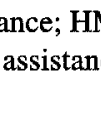 & & 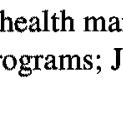 & & & & & \\
\hline
\end{tabular}


the number of group treatment sessions $(p<.10)$. The number of managed care clients shows no significant relationship with treatment intensity. The percentage of revenues from managed care shows a marginal, positive relationship with months in treatment $(p<.10)$.

Three additional organizational factors significantly influence treatment intensity. The percentage of total staff who are professionals displays a negative and significant relationship with the number of group treatment sessions $(p<.05)$. Finally, private, for-profit ownership displays a marginally significant association with group sessions received over the course of treatment $(p<.10)$.

There is consistent evidence that methadone units provide treatment that lasts longer and includes more individual and group treatment sessions. Specifically, the methadone status variable shows positive associations with the number of months in treatment $(p<.01)$, individual treatment sessions $(p<.01)$, and group treatment sessions $(p<.10)$. One other client mix factor is associated with treatment intensity. The percentage of clients unemployed was found to be positively associated with group treatment sessions $(p<.01)$.

\section{Additional analyses}

The primary goal of this study was to investigate the main effects of managed care oversight scope and stringency on substance abuse treatment intensity. Variation in the types of OSAT units in the sample and the degree to which units are involved in managed care, however, may suggest that the effects of managed care scope and stringency on treatment intensity may only hold under certain conditions. To explore other potential relationships, additional analyses were conducted.

First, the possibility that the effects of managed care scope and stringency are conditional on the degree to which the OSAT unit is dependent on managed care was explored. Variables representing the interaction of (1) managed care oversight scope and percentage of revenues covered by managed care and (2) managed care oversight stringency and percentage of revenues covered by managed care were created and tested. Significant effects of these interaction terms would suggest that the effects of managed care scope and stringency are conditional on the unit's dependence on managed care. No interaction terms were found to be significant.

Next, the possibility that the effects of managed care oversight scope and stringency are different for clients covered by managed care versus clients not covered by managed care was examined. To address this possibility, the set of predictors was regressed on two measures of treatment intensity among managed care clients in each unit. The measures of treatment intensity were (1) the proportion of managed care clients remaining in treatment for 6 months or longer and (2) the proportion of managed care clients who received 20 or more treatment sessions over the course of treatment. Results obtained from generalized linear regression estimation are consistent with those reported for all clients. That is, findings suggest no systematic relationship between managed care oversight scope and treatment intensity for managed care clients. The stringency of managed care oversight, however, was negatively associated with both measures of treatment intensity among managed care clients.

Last, the possibility that managed care has different effects on the intensity of treatment in methadone units and in non-methadone units was explored. Terms representing the interaction of (1) managed care oversight scope and methadone treatment status and (2) managed care oversight stringency and methadone treatment status were created and tested. Significant effects of these interaction terms would suggest that the effects of managed care scope and stringency are conditional on whether or not the unit provided methadone treatment services. Only one of the six interaction terms was found to be significant. The term representing methadone treatment and managed care oversight scope was significant in the model estimating the number of group sessions provided over the course of treatment. Specifically, managed care oversight scope has a significant negative effect on group treatment sessions in methadone units. This effect, however, does not hold for nonmethadone units. No other interaction terms for methadone and managed care oversight were found to be significant. 


\section{Implications for Behavioral Health Services}

\section{Managed care selection}

This study provides evidence that managed care influences outpatient substance abuse treatment through the process by which units are selected by managed care firms or choose to participate in managed care programs. In other words, treatment intensity is systematically related to whether or not the OSAT unit participates in managed care. Specifically, units that participate in managed care have shorter treatment duration and provide fewer individual sessions over the course of treatment.

While selection bias has been accounted for in this examination of the effects of managed care oversight on treatment intensity, the implications of such systematic selection also must be addressed. On one hand, the selection of high-quality, efficient organizations for managed care participation could ultimately improve the overall treatment system. As less efficient, lower-quality organizations are left out of managed care programs, they may be unable to survive. Their exit would leave a more efficient, high-quality system of providers. On the other hand, if specific types of treatment organizations are excluded by (or choose not to participate in) managed care, such as public units, methadone treatment providers, small units, and those that are not owned or managed by another organization, this may create critical access issues for those in need of substance abuse treatment. In sum, the process by which treatment organizations choose to participate in (or are chosen for) managed care programs is not random and has implications for substance abuse treatment processes, and ultimately, the nation's treatment system.

\section{Managed care oversight}

Results from these analyses suggest that there are differences in the levels of treatment intensity between OSAT units involved in managed care and those not involved in managed care. After controlling for managed care selection, as well as several environmental and organizational characteristics, the scope of managed care oversight does not influence treatment intensity in any systematic fashion. Greater managed care oversight stringency, however, shows a clear, negative association with treatment intensity in OSAT units.

Managed care firms and treatment organizations dedicate significant resources to oversight activities, including preauthorization, utilization review, treatment planning, ongoing correspondence, and post-treatment review. While the scope of managed care oversight does not directly influence treatment intensity, it is important to consider that managed care oversight may have other effects on OSAT units. For example, OSAT units may incur substantial costs as they handle the many diverse oversight requirements of managed care. In addition, when oversight activities apply to a greater percentage of clients, OSAT units may incur other nonfinancial costs including increased frustration of staff and increased confusion for clients. Managed behavioral care programs may be better served by doing away with direct behavioral control in favor of other ways of managing care and costs, such as careful review and selection of providers and the use of capitated payment schemes.

This article presents evidence that OSAT providers are forced to change accepted treatment practices when managed care firms exert stringent visit limits, thus confirming a widely held belief that constraints imposed by managed care lead to less intense substance abuse treatment. The study also finds that managed care oversight limits treatment intensity in both methadone and nonmethadone settings. Oversight stringency may be more effective than oversight scope in influencing treatment because it involves more direct sanctions or penalties for noncompliance. Thus, if visits are provided beyond those authorized by managed care firms, OSAT units are not reimbursed for the services provided in those visits. This greater degree of enforcement, vigilance, and sanctions may increase organizational compliance. ${ }^{32}$

The finding that greater stringency is effective in reducing treatment intensity has several important implications for managed care policy. Historically, visit limits were often determined in 
at least two ways in managed care programs. First, visit limits for substance abuse services are often part of the benefit design in managed behavioral care. While specific plans vary substantially, managed behavioral care benefit packages typically include specific limits on the number of substance abuse sessions that are covered by the plan in a 12-month period. ${ }^{48}$ Second, managed care firms restrict visits through preauthorization and various forms of concurrent and post-discharge utilization review. The number of visits in the benefit package is often described as "theoretical visits" because the actual number of visits that will be reimbursed is determined through ongoing correspondence between OSAT staff and the managed care firm. This study provides clear evidence that more stringent limits constrain drug treatment intensity. These findings should be considered as new public and private managed care programs are developed and also as new federal guidelines are established. For example, this study provides empirical support for some managed care oversight activities that are currently being developed and implemented by some managed behavioral care plans, including the use of medical necessity criteria to determine the number of sessions covered, rather than using arbitrary visit limits.

Taking a more comprehensive approach to substance abuse treatment oversight is important. If visit limits are too severe, clients will have reduced opportunities to achieve positive treatment outcomes. As new managed care policies and programs are developed, efforts should also be made to include coverage for additional types of services, including aftercare and other services that may achieve desired treatment outcomes even though clients may have fewer face-to-face therapy visits.

\section{Limitations}

The NDATSS is a comprehensive, ongoing body of research on OSAT organizations and thus includes aggregate data reported by the administrative and clinical leaders of outpatient treatment facilities. It is important to note that unit directors provide estimates of treatment intensity for the entire population of clients served in the organization. Despite the fact that study results compare favorably with data reported from client-level research, it is possible that the estimates made by unit directors may differ from actual lengths of stay and the number of treatment sessions received by clients. Further, the data do not permit an analysis of how managed care oversight and treatment intensity are associated with treatment outcomes for individual substance abuse treatment clients. Without client-specific data, this research cannot demonstrate how shorter, less intense treatment may affect various post-treatment outcomes. Nevertheless, this study provides an important organizational-level perspective on the relationships between managed care and treatment duration. Further research is needed to clearly identify and measure specific relationships between managed care oversight, treatment intensity, and various treatment outcomes.

\section{Conclusion}

Managed care holds both the promise of improving the drug treatment system and the potential of limiting treatment services. This study provides important insights into what happens at the intersection of these two societal trends. Further work is needed, however, to understand more specifically how providers deal with conflicting demands regarding treatment practices and, ultimately, how these demands influence the effectiveness of substance abuse treatment. This investigation lays the ground work for future research that may increase our understanding of the role of managed care in a comprehensive solution to the consequences of addiction.

\section{Acknowledgments}

An earlier version of this article was presented as a poster at the 1999 Association for Health Services Research meeting. This research was supported by grants 5R01-DA03272 and 5R01- 


\section{References}

1. Mechanic D, Schlesinger M, McAlpine DD. Management of mental health and substance abuse services: state of the art and early results. The Milbank Quarterly. 1995;73(1):19-55.

2. Wells KB, Astrachan BM, Tischler GL, et al. Issues and approaches in evaluating managed mental health care. The Milbank Quarterly. $1995 ; 73(1): 57-75$.

3. Findlay S. Managed behavioral health care in 1999; an industry at a crossroads. Health Affairs. 1999;18(5):116-124.

4. Manderscheid RW, Henderson MJ. Speaking with a Common Language: The Past, Present and Future of Data Standards for Managed Behavioral Healthcare. Rockville, MD: Center for Mental Health Services, Division of State and Community Systems Development; 1995.

5. Mechanic D, McAlpine DD. Mission unfulfilled: potholes on the road to mental health parity. Health Affairs, 1999;18(5):7-21.

6. McLellan AT, Woody GE, Metzger D, et al. Evaluating the effectiveness of addiction treatment: reasonable expectations, appropriate comparisons. In: Egerton JA, Fox DM, Leshner AI, eds. Treating Drug Abusers Effectively. Malden, MA: Blackwell; 1997.

7. Bell DC, Richard AJ, Feltz LC. Mediators of drug treatment outcomes. Addictive Behaviors. 1996;21(5):597-613.

8. Ershoff $\mathrm{D}$, Radcliffe A, Gregory M. The southern California Kaiser-Permanente chemical dependency recovery program evaluation: results of a treatment outcome study in an HMO setting. Joumal of Addictive Diseases. 1996;15(3):1-25.

9. Hoffmann NG, Miller NS. Treatment outcomes for abstinence-based programs. Psychiatric Annals. 1992;22(8):402-408.

10. Hubbard RL, Marsden ME, Rachal JV. Drug Abuse Treatment: A National Study of Effectiveness. Chapel Hill, NC: University of North Carolina Press; 1989.

11. McKay JR, Alterman AI, McLellan AT, et al. Treatment goals, continuity of care and outcomes in a day hospital substance abuse rehabilitation program. American Journal of Psychiatry. 1994;151(2):254-259.

12. Moos RH, Finney JW, Cronkite RC. Alcoholism Treatment: Content, Process, and Outcome. New York: Oxford University Press; 1990.

13. Simpson DD. Effectiveness of drug-abuse treatment: a review of research from field settings. In: Egerton JA, Fox DM, Leshner AI, eds. Treating Drug Abuse Effectively. Malden, MA: Blackwell Publishers; 1997.

14. Campbell J, Gabrielli W, Laster LJ, et al. Efficacy of outpatient intensive treatment for drug abuse. Journal of Addictive Diseases. $1997 ; 16(2): 15-25$.

15. Higgins ST, Budney AJ, Bickel WK, et al. Participation of significant others in outpatient behavioral treatment predicts greater cocaine abstinence. American Journal of Drug and Alcohol Abuse. 1993;20(1):47-56.

16. Hoffman JA, Caudill BD, Koman JJ III, et al. Comparative cocaine abuse treatment strategies: enhancing client retention and treatment exposure. Journal of Addictive Diseases. 1994;13(4):115-128.

17. Kang S, Kleinman PH, Woody GE. Outcomes for cocaine abusers after once-a-week psychosocial therapy. The American Joumal of Psychiatry. 1991;148:630-635.

18. Simpson DD. Joe GW, Rowan-Szal G, et al. Client engagement and change during drug abuse treatment. Joumal of Substance Abuse. $1995 ; 7(1): 117-134$.

19. Edmunds M, Frank R, Hogan M, et al, eds. Managing Managed Care: Quality Improvements in Behavioral Health. Washington, DC: National Academy Press; 1997.

20. Beinecke RH, Goodman M, Lockhart A. The impact of managed care on Massachusetts mental health and substance abuse providers. Administration in Social Work. 1997;21(2):41-53.

21. French MT, Dunlap LJ, Galinis BA, et al. Health care reforms and managed care for substance abuse services: findings from eleven case studies. Joumal of Public Health Policy. 1996;17(2):181-203.

22. Miller WR. The effectiveness of treatment for substance abuse: reasons for optimism. Journal of Substance Abuse Treatment. 1992;9:93102.

23. Alexander JA, Lemak CH. Managed care penetration in outpatient substance abuse treatment units. Medical Care Research and Review. $1997,54(4): 490-507$.

24. Alexander JA, Lemak CH. Directors' perceptions of the effects of managed care on outpatient substance abuse treatment. Joumal of Substance Abuse. 1997;9:1-14.

25. Alexander JA, Lemak CH. The effects of managed care on administrative burden in outpatient substance abuse treatmentfacilities. Medical Care. 1997;35(10):1060-1068.

26. Alexander JA, Wheeler JRC, Nahra T, et al. Managed care and technical efficiency in outpatient substance abuse treatment units. Joumal of Behavioral Health Services and Research. 1998;25(4):377-396.

27. Substance Abuse and Mental Health Services Administration. Overview of the National Drug and Alcohol Treatment Unit Survey (NDATUS): 1992 and 1980-1992. Advance Report No. 9. Rockville, MD: Author: 1995.

28. Pfeffer J, Salancik G. The External Control of Organizations: A Resource Dependence Perspective. New York: Harper \& Row: 1978.

29. Hasenfeld YE. The Organization of Human Services: Structure and Processes. Beverly Hills, CA: Sage: 1992.

30. D'Aunno T, Sutton RI, Price RH. Isomorphism and external support in conflicting institutional environments: a study of drug abuse treatment units. Academy of Management Journal. 1991;34(3):636-661.

31. Flynn DM. Sponsorship and the survival of new organizations. Joumal of Small Business Management. January 1993:51-62.

32. Oliver C. Strategic responses to institutional processes. Academy of Management Review. 1991;16(1):145-179.

33. Wheeler JRC, Fadel H, D'Aunno TA. Ownership and performance of outpatient substance abuse treatment centers. American Journal of Public Health. 1992;82(5):711-718.

34. Etheridge R, Hubbard RL, Anderson J, et al. Treatment structure and program services in the Drug Abuse Treatment Outcome Study (DATOS). Psychology of Addictive Behaviors. 1997;11(4);244-260. 
35. Simpson DD, Savage LJ, Lloyd MR. Follow-upevaluation of treatment of drug abuse during 1969 to 1972. Archives of General Psychiatry. 1979;36:772-780.

36. Simpson DD. Treatment for drug abuse: follow-up outcomes and length of time spent. Archives of General Psychiatry, 1981:38:875-880.

37. Alemi F, Stephens RC, Llorens $\mathrm{S}$, et al. A review of factors affecting treatment outcomes: expected treatment outcome scale. American Journal of Drug and Alcohol Abuse. 1995;21(4):483-509.

38. Joe GW, Simpson DD, Sells SB. Treatment process and relapse to opioid use during methadone maintenance. American Journal of Drug and Alcohol Abuse. 1992:19:124-130.

39. McLellan AT, Alterman Al, Metzger DS. et al. Similarity of outcome predictors across opiate, cocaine, and alcohol treatments: role of treatment services. Journal of Consulting and Clinical Psychology. 1994;62(6):1141-1158.

40. Ornstein P, Cherapon JA. Demographic variables as predictors of alcoholism treatment outcome. Journal of Studies on Alcohol. $1985 ; 46(5): 425-432$.

41. Groves RL. Telephone Survey Methodology. New York: Wiley; 1988.

42. D'Aunno T. Vaughn TE, McElroy P. An institutional analysis of HIV prevention efforts by the nation's outpatient substance abuse treatment units. Journal of Health and Social Behavior. 1999;40:175-192.

43. Batten HL, Prottas JM. Horgan CM, et al, eds. Drug Services Research Survey, Final Report: Phase II. Waltham, MA: Institute for Health Policy, Brandeis University; 1992.

44. Shwartz M, Mulvey KP, Woods D. et al. Length of stay as an outcome in an era of managed care: an empirical study. Journal of Substance Abuse Treatment. 1997;14(1):11-18.

45. Heckman JJ. Sample selection bias as a specification error. Econometrica. 1979;47:153-161.

46. Breen R. Regression Models: Censored, Sample-Selected, or Truncated Data. Thousand Oaks, CA: Sage; 1996.

47. Lemak $\mathrm{CH}$, Alexander JA. D'Aunno TA. Organizational analysis of selective contracting in managed care: the case of substance abuse treatment. Working paper, 1999.

48. Goldman W, McCulloch J, Cuffel B, et al. More evidence for the insurability of managed behavioral health care. Health Affairs. 1999:18(5):172-181.

49. Nurco DN, Kinlock TW, Hanlon TE. The nature and status of drug abuse treatment. Maryland Medical Journal. 1994:43(1):51-57.

50. Wheeler JRC, Nahra TA. Private and public ownership in behavioral health care: do we have a two-tiered system? Administration and Policy in Mental Health. 2000;27(4):197-209. 


\section{Appendix A}

\section{Participation Model}

This appendix provides details of the participation model used in the sample selection analyses. The conceptual model suggests that outpatient substance abuse treatment (OSAT) unit participation in managed care will be a function of several environmental and organizational characteristics. The full details of the model have been presented elsewhere. ${ }^{47}$ The hypothesized relationships between organizational and environmental characteristics and unit participation in managed care were developed from previous research ${ }^{28.33 .49 .50}$ and are summarized in Table A-1. In addition, measurement of study variables is described. Descriptive statistics and bivariate correlations for participation model variables are shown in Table A-2.

\section{Measurement}

The following variables are included only in the participation equation. All other participation equation variables are included in the main model regression and have been described in the body of this article.

- Managed care participation-The dependent variable in the participation equation is a categorical variable that is equal to 1 for those OSAT organizations that reported that more than 10 OSAT clients were covered by managed care arrangements during the most recent complete fiscal year.

- Competition-This variable is measured by a factor score that was created using principal components factor analysis (regression method). Two distinct factors emerged in the analysis of 10 different items dealing with competition of the OSAT unit. One of the two factor scores is included, competition for costs, which is based on five items measuring the degree of competition for the cost of treatment to clients, the costs of treatment to payment sources other than clients, marketing efforts, pricing strategies, and cost control strategies.

\section{Table A-1}

Variable and suggested relationship with unit participation in managed care

Managed care penetration in market

Positive

Competition

Positive

Affiliation with a hospital

Positive

Affiliation with a mental health center

Positive

Larger size

Positive

Methadone treatment modality

Negative

Referrals from health care organizations/employee assistance programs

Positive

Joint Commission accreditation

Positive

Private, for-profit ownership

Positive

Private, not-for-profit ownership

Positive 





- Referrals from health care organizations and employee assistance programs-The clinical supervisor of each OSAT unit reported the percentage of clients referred by a variety of referral sources. The percentages from four categories of referral sources that reflect provider organizations and those most likely to be involved in managed care (substance abuse treatment facilities, mental health agencies, hospitals/physicians/general health care providers, and employee assistance programs) were summed to create one measure of the overall percentage of client referrals from providers or managed care-related organizations.

- Joint Commission accreditation-This variable is used as a proxy measure of organizational quality. Units with Joint Commission accreditation were coded 1; all other units were coded 0. 